\title{
Wybrane aspekty bioinspiracji w procesach spawalniczych
}

\author{
Some aspects of bioinspirations \\ in welding processes
}

\section{Streszczenie}

Bionika jest dziedziną nauki, która bada budowę organizmów żywych (roślin, zwierząt), biomateriałów wytwarzanych przez organizmy żywe oraz procesów występujących w przyrodzie $\mathrm{w}$ celu wykorzystania ich $\mathrm{w}$ technice. Jednym z bardzo interesujących aspektów wykorzystania osiągnięć bioniki jest projektowanie lekkich konstrukcji w oparciu o analizę i modelowanie budowy roślin czy szkieletów zwierząt oraz poprawa właściwości warstwy wierzchniej elementów (np. po napawaniu) przez zastosowanie niepłaskich powierzchni analogicznych do występujących w przyrodzie. Tym właśnie zagadnieniom poświęcony jest artykuł.

Słowa kluczowe: bioinspiracje; konstrukcje lekkie; konstrukcje spawane; napawanie; struktura powierzchni

\begin{abstract}
Bionic is a branch of knowledge, which investigated structures of alive organisms (plants and animals), biomaterials created by plants or animals and processes occurring in the Nature in order to inspire technical problems rational solution. One of very interested area of bionic achievements application is designing of lightweight constructions. Here the source of biological inspiration are structures of plants and animals skeletons. Another area of bionic inspiration could be improvement of details surface properties (after alloying) by application of non-smooth surfaces analogous to this which the Nature created in evolution process.
\end{abstract}

Keywords: bio-inspirations; lightweight designing; welding construction; alloying, surface structure

\section{Wstęp}

Technologie spawalnicze wykorzystywane są do łączenia elementów w każdej gałęzi techniki od budownictwa przez przemysł sprzętu gospodarstwa domowego, maszynowy, samochodowy czy okrętowy do lotniczego i kosmicznego [1]. Wykorzystując rozwijające się dynamicznie technologie spawania stali, żeliwa, metali kolorowych oraz ich stopów możliwe jest wytwarzanie złożonych elementów różnych wymiarów, których wykonanie innymi metodami byłoby niezwykle trudne, nieekonomiczne lub niemożliwe. Istotną role w kształtowaniu właściwości warstwy wierzchniej nowych elementów oraz wszechstronnie rozumianej regeneracji wyrobów odgrywają technologie napawania. specjalnych warstw, które przedłużają okres eksploatacji elementów, obniżając koszty (element poza warstwa wierzchnią o odpowiednio dobranej grubości może zwykle być wykonany z tańszego materiału) i dając ogromne możliwości regeneracji zużytych elementów $[2,3]$. W obszarze spawania czy napawania zachodzą niezwykle skomplikowane i trudne do sterowania procesy cieplne (topienie, mieszanie składników, przemiany strukturalne, krzepniecie itp.) Od ich poznania i możliwości sterowania ich przebiegiem zależy jakość połączenia i właściwości napawanej warstwy [1 $\div 5]$. Technologie spawania i napawania rozwijają się niezwykle dynamicznie i kompleksowo. Dlatego trudno jest zidentyfikować obszar, który można wskazać jako innowacyjny kierunek badań.
Pewne możliwości nowego spojrzenia na rozwój technologii spawania i napawania z osiągnięć „bioniki” - dziedziny nauki, która bada organizmy żywe oraz materiały i procesy wystepujące w przyrodzie z punktu widzenia możliwości ich

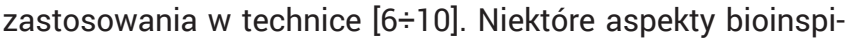
racji możliwe do ewentualnego uwzględnienia w technologiach spawania i napawania zostaną przedstawione poniżej.

\section{Charakterystyka struktur występujących w przyrodzie}

Obecnie występujące formy roślin i zwierząt są wynikiem trwającego wiele milionów lat procesu ewolucji. Organizmy, które nie przystosowały się do zmian występujących w środowisku wyginęły. Widok drzew, które występują prawie we wszystkich ekosystemach lądowych jest tak pospolity, że nie zauważamy optymalnych rozwiązań, które tutaj Natura wypracowała $[6,11,12]$. Rozwidlenia i połączenia gałęzi są rozwiązane optymalnie ze względu na przenoszenie obciążeń statycznych i dynamicznych (wiatr, deszcz, śnieg, zmiana temperatury itp.). Optymalny jest również rozkład naprężeń w obszarze rozwidleń. Należy podkreślić, że również struktura wewnętrzna drzew, krzewów bambusa czy sitowia jest optymalna i zapewnia odpowiednią sztywność,

Prof. dr hab. inż. Adam Ruszaj - Politechnika Krakowska.

Autor korespondencyjny/Corresponding author. ruszaj@mech.pk.edu.pl 
elastyczność i odporność na zużycie. Podobnie liście drzew, czy kwiatów wodnych, które pełnią wiele funkcji (proces fotosyntezy, oddychanie, regulacja wilgotności i temperatury) mają niezwykłą strukturę wewnętrzną (użyłkowanie) na której można się wzorować w projektowaniu elementów. Zwierzęta także charakteryzują się niezwykłym przystosowaniem do warunków, w których żyją. Można tutaj omawiać wiele aspektów przystosowania do warunków życia. Ze względu na tematykę poruszanych zagadnień szczególną uwagą należy zwrócono na fakt, że w przyrodzie praktycznie nie ma gładkich płaskich powierzchni oraz linii pro-

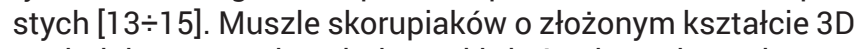
posiadają na powierzchni prążki, które istotnie podnoszą ich odporność na zużycie. Zwierzęta ziemne są szczególnie przystosowane do trudnych warunków. Pospolity żuk gnojowy ma powierzchnię skrzydeł prążkowaną a na tułowiu i głowie można zaobserwować odpowiednio wgłębienia i występy. Zmniejszają one powierzchnie kontaktu z ziemią a puste przestrzenie wypełniają się wodą lub powietrzem zapewniając smarowanie a w konsekwencji zmniejszając opory ruchu. Podnosi to „efektywność pracy” żuka i zmniejsza możliwość uszkodzenia powierzchni jego skrzydeł, głowy czy tułowia. Łapy kreta mające specyficzny kształt zapewniający optymalne rozdrabnianie i usuwanie ziemi stanowiły inspiracje do zaprojektowania elementów tnących w maszynach rolniczych. Szkielety ptaków czy ssaków mają również optymalną lekką budowę i strukturę wewnętrzna niezbędną do przenoszenia obciążeń oraz tłumienia drgań. Powyższe cechy budowy roślin i zwierząt można wykorzystać w technice między innymi do projektowania lekkich spawanych konstrukcji oraz do poprawy właściwości użytkowych warstwy wierzchniej elementów wykonanych z żeliwa czy powierzchni lemiesza koparki $[8,11,13,14,15]$.

\section{Metodyka wprowadzania bioinspiracji}

W projektowaniu „bionicznym” można wyróżnić przedstawione poniżej etapy $[6 \div 11]$.

- sformułowanie problemu i celu technicznego

- przeprowadzenie kompleksowej analizy struktur biologicznych w celu wyboru i wstępnej oceny praktycznej przydatność modelu biologicznego

- opracowanie w oparciu o model biologiczny modelu technicznego oraz modelowanie matematyczne (często metodą elementów skończonych (Finite Elements Method - FEM), jego właściwości (np.tłumienie drgań, sztywność, rozkład naprężeń itp.).

- opracowanie na podstawie wyników modelowania matematycznego modelowych elementów do badań doświadczalnych; w przypadku modelowania dużych elementó (np. korpus obrabiarki) model wykonuje się w odpowiedniej skali (np. 1:4 czy 1:6 itp.); do wykonania modelu stosuje się tradycyjne metody wytwarzania NC i CNC, spawanie, odlewanie oraz coraz częściej metody przyrostowe.

- przeprowadzenie wszechstronnych badań modelu i uogólnienie uzyskanych wyników na rzeczywisty obiekt w celu oceny zmniejszenia masy, zwiększenia sztywności, wytrzymałości, wielkości odkształceń, rozkładu naprężeń, charakterystyk dynamicznych itp.

- ocena stopnia realizacji (spełnienia) celu technicznego. Jeżeli cel został spełniony to zostaje wykonany prototyp funkcjonalny; jeżeli cel nie został spełniony to można podjąć działania korygujące model bioniczny, doświadczalny czy metodykę obliczeń.

Należy podkreślić, że w całym cyklu badań niezwykle ważnym narzędziem badawczym jest intuicja. W zakresie rozwoju lekkich konstrukcji spawanych dynamicznie rozwija się metodyka związana z wykorzystaniem rozwiązań konstrukcyjnych, które możemy obserwować w drzewach, krzewach czy liściach (np. kwiatów wodnych, kaktusa czy

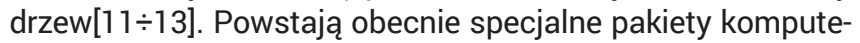
rowe (np. Pakiet Performance Control) wspomagajęce proces projektowania bionicznego, które umożliwiają projektantowi dokonywanie (na bieżąco) porównania projektu powstającego wg dotychczas stosowanych konwencjonalnych zasad z alternatywnym projektem bionicznym opartym na strukturach naturalnych drzew. Na przykład konstruktor może na bieżąco ocenić o ile może zmniejszony został ciężar konstrukcji bez zmniejszenia sztywności czy wytrzymałości [11].

\section{Charakterystyka konstrukcji lekkich}

Konstrukcje lekkie [6] to konstrukcje o zminimalizowanej masie ale zachowujące pozostałe właściwości użytkowe na przynajmniej niezmienionym poziomie w stosunku do rozwiązań konwencjonalnych. Te pozostałe właściwości to: funkcjonalność i bezpieczeństwo związane z wytrzymałością, sztywnością i odpornością na zużycie, ekologicznością itp. Tworzenie konstrukcji lekkich w ujęciu konwencjonalnym jest obecnie związane ze stosowaniem w możliwe największym zakresie lekkich materiałów takich jak: metale lekkie (Lit, Magnez, Beryl, Aluminium i Tytan) i ich stopy, specjalne materiały kompozytowe, tworzywa sztuczne oraz odpowiednie nowoczesne, optymalne rozwiązania konstrukcyjne (np. zastosowanie monolitycznych turbin lotniczych tzw. „blisks” zamiast tradycyjnych składanych z oddzielnie wykonywanych łopatek montowanych w specjalnych zamkach na pierścieniu [6]. Jednak badania wykazują, ze najnowocześniejsze i najbardziej efektywne rozwiązania w zakresie konstrukcji lekkich oferuje Natura [6,7,13]: Zastosowanie scharakteryzowanej powyżej metodologii oraz osiągnięć "bioniki" umożliwiło opracowanie konstrukcji korpusów obrabiarek, elementów lotniczych czy innych elementów o znacznie polepszonych charakterystykach. Elementy charakteryzowały się większą wytrzymałością (53-124\%), i sztywnością (21-43\%), zmniejszoną masą (3-43\%) i mniejszymi odkształceniami (16-44\%) Przykłady zostaną przedstawione poniżej.

\section{Bioniczna konstrukcja „bramy” obrabiarki}

Poniżej zostanie przedstawiony przykład konwencjonalnej i bionicznej konstrukcji przesuwnej bramy (portalu) obrabiarki z nieruchomym stołem (Lin MC 600) [13]. Jako biologiczny wzorzec przyjęto liście lilii wodnej i kaktusa. Liść lilii wodnej przedstawiono na rysunku 1.

Bioniczna konstrukcja (Rys.2b) charakteryzuje się mniejszymi odkształceniami( 16,22\%), mniejszą masą ( 3,31\%)
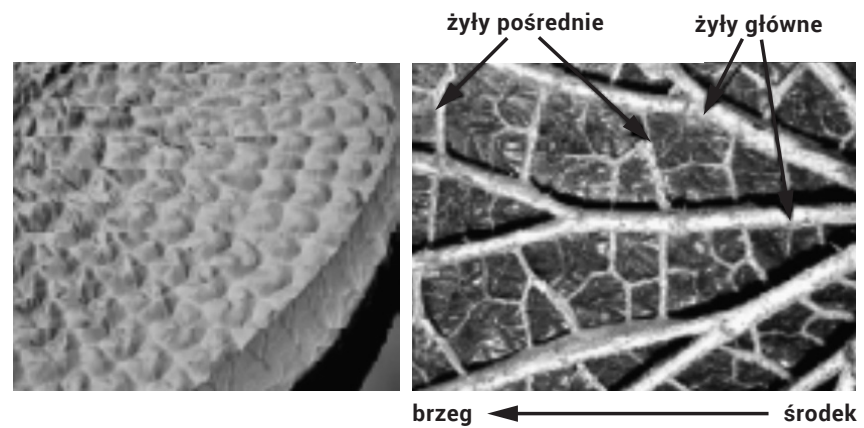

Rys. 1. Liść lilii olbrzymiej (po lewej) oraz struktura jego użyłkowania (po prawej) [13]

Fig. 1. The giant waterlily leaf (on the left) and its veins distribution (on the right) [13] 
a)

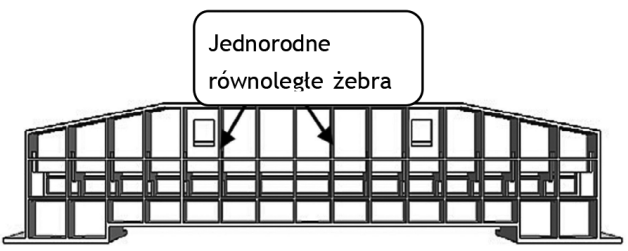

b)

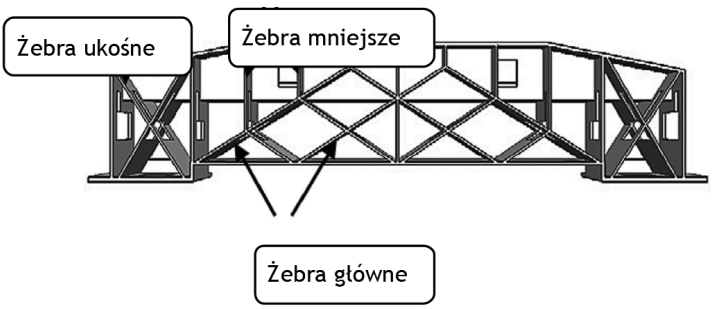

Rys. 2. Konstrukcja konwencjonalna z jednakowymi równoległymi żebrami (a) oraz udoskonalona bioniczna konstrukcja (b) [13]

Fig. 2. The conventional construction with pararell and uniform ribs (a) and the improved bionic construction (b) [13]

oraz większą sztywnością ( 17,33\%) w stosunku do bramy zaprojektowanej w tradycyjny sposób (Rys.2a). Równocześnie poprawie uległy charakterystyki dynamiczne (odporność na drgania) bramy [13]

Poprawa właściwości użytkowych w bionicznej konstrukcji jest bezsporna. Jednak jej wykonanie może być trudniejsze niż w przypadku bramy konwencjonalnej (żebra ukośne o różnych długościach, trudniejszy dostęp itp.). Decyzja o ewentualnym praktycznym zastosowaniu powinna być oparta na wynikach optymalizacji dla przyjętych kryteriów.
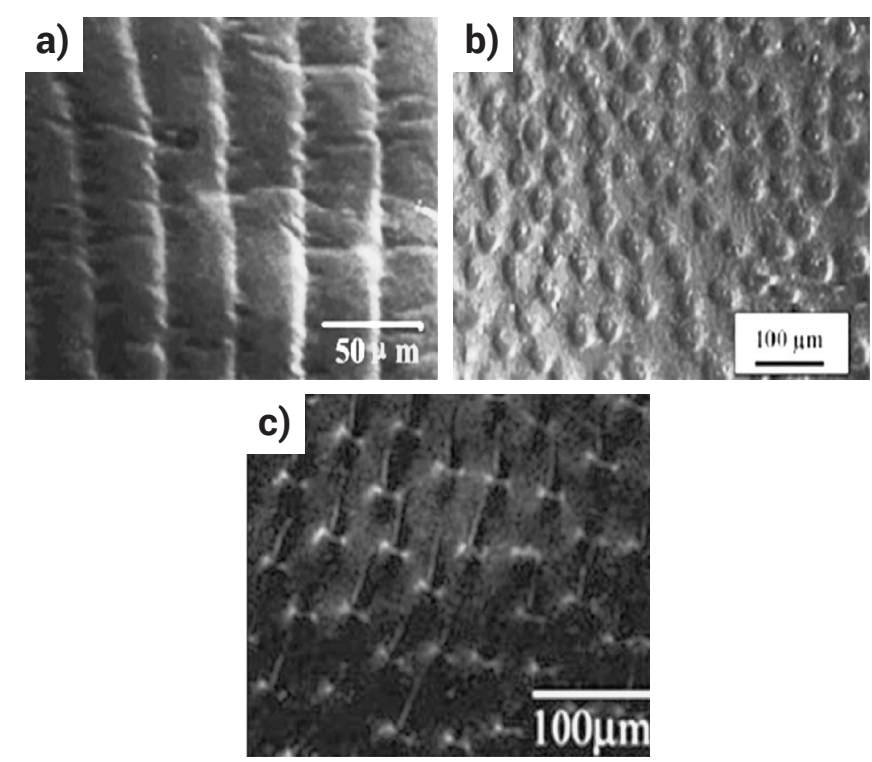

Rys. 3. Trzy rodzaje struktury występujących u żuka gnojowego: a) struktura paskowa występująca na pokrywie skrzydła, b) struktura powierzchni głowy, c) siatka na głowie uformowana ze krowiego nawozu [14]

Fig. 3. Three kinds of soil animals surfaces: a) stripshape of dung beetle's elytrum, b) punctuate shape of dung beetle's head, and c) reticulate of cow muck dung beetle's head [14]

\section{Kształtowanie właściwości warstwy wierzchniej}

W badaniach jako wzór struktury powierzchni przyjęto strukturę powierzchni skrzydeł, tułowia i głowy żuka gnojowego (rys.3) $[9,14]$.

Wzorując się na strukturach z rysunku 3. przygotowano próbki z kilkunastoma wariantami struktury wykonanymi laserem Nd-Yag. Przykłady tych struktur przedstawia rysunek 4.

Przeprowadzone badania próbek ustrukturyzowanych laserowo wykazały, że wszystkie próbki z bioniczna strukturą powierzchni wykazują większą odporność na zużycie zmęczeniowe w stosunku do próbek o powierzchni płaskiej. Wzrost ten wynosi: $53 \%$ dla próbek z bioniczną strukturą siatkową (kąt krzyżowania się rowków 600), 29\% dla próbek $\mathrm{z}$ bioniczna strukturą $\mathrm{w}$ postaci równoległych rowków oraz $22 \%$ dla próbek z punktowymi wgłębieniami. Wzrost wytrzymałości zmęczeniowej powyższych próbek wynika przede wszystkim z opóźnienia pojawiania się mikropęknięć oraz hamowania i zmiany kierunku ich propagacji. Wadą laserowego strukturyzowania powierzchni jest wprowadzenie lokalnych zmian właściwości próbki (naprężenia rozciągające, obniżenie twardości itp.). Zlikwidowanie tych zmian i ujednorodnienie właściwości mechanicznych można uzyskać przez wprowadzenie obróbki wykończeniowej Shock Laser Processing (SLP) [15]. Połączenie napawania z bionicznym strukturyzowaniem i SLP (obróbka wykończeniowa) może prowadzić do uzyskania unikalnych właściwości powierzchni (naprężenia wewnętrzne ściskające, wzrost twardości, wytrzymałości, odporności na żużycie, odorności na korozję itp.).

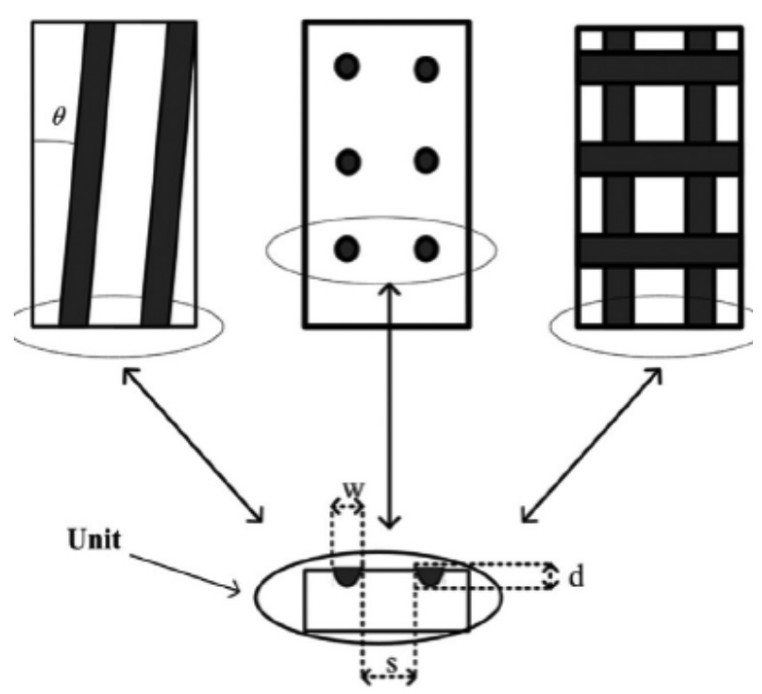

Rys. 4. Przykłady struktury bionicznej powierzchni próbek z żeliwa szarego $\mathrm{GCl}$ wzorowanej na strukturze przedstawionej na rys.3. $\mathrm{s}$ - odległość elementów struktury, W - wymiar struktury (średnica lub szerokość), d - głębokość śladu struktury [14]

Fig. 4. Example of samples made of grey iron GCI with bionic surface structure design taking into account Fig.3.; s - distance between structure elements, $\mathrm{W}$ - dimension of structure elements (diameter or width), $d$ - depth of structure elements [14]

\section{Podsumowanie}

W powyższych rozważaniach zwrócono uwagę na niektóre aspekty możliwość wykorzystania bioinspiracji w technologiach spawania i napawania. W zakresie spawania bioinspiracja jest pośrednia. Konstrukcje lekkie spawane projektuje się z wykorzystaniem bioinspiracji w celu zmniejszenia masy, wzrostu sztywność, zmniejszenia odkształceń, zwiększenie 
zdolności tłumienia drgań itp. Aby odpowiedzieć na pytanie: jak wprowadzenie bioinspiracji w takiej konstrukcji wpłynie na operacje spawalnicze trzeba przeprowadzić stosowna analizę. Być może operacje spawalnicze w bionicznej konstrukcji będą trudniejsze i bardziej kosztowne (większa liczba żeber o różnych wymiarach w stosunku do konwencjonalnej konstrukcji, dodatkowe pochyłe żebra o różnej długości). Ale ostatecznie może zostać wytworzony produkt o wyższej jakości i mniejszym zużyciu materiałów, co może poprawić efektywność takiej produkcji. Ostatecznie decydować będzie analiza efektywności w każdym indywidualnym przypadku. W przypadku technologii napawania odpowiedź może być bardziej jednoznaczna. Wytworzenie odpowiedniej struktury na napawanej powierzchni zapewne poprawi jej właściwości (np. odporność na zużycie zmęczeniowe). Efekty zależeć będą od koniecznych operacji wykończeniowych wspomagających napawanie (np. obróbka zgniotem) [2,3]. Połączenie technologii napawania ze strukturyzowaniem i SLP może dać największe efekt wynikające z poprawy właściwości warstwy wierzchniej [15]. Z uwagi na to, że praktyczne zastosowania osiągnięć bioniki to nie tylko chwilowa moda ale trwały kierunek rozwoju konstrukcji i procesów produkcyjnych celowe jest uwzględnienie w pracach badawczych, rozwojowych i procesach wytwarzania osiągnięć „Bioniki”

\section{Literatura}

[1] E.Tasak .: Metalurgia spawania. Wyd. JAK Kraków 2008.

[2] J. Radziejewska (Praca habilitacyjna], Laserowa modyfikacja właściwości warstwy wierzchniej wspomagana nagniataniem Prace IPPT PAN, $\mathrm{Nr}$ $3 / 2011$.

[3] A. Dmowska, „Badania warstwy wierzchniej elementów nagniatanych powierzchniowo po stopowaniu elektroiskrowym", Rozprawa doktorska, Politechnika Warszawska, Wydział Inżynierii Produkcji, Warszawa 2015.

[4] J. Kozak, Z. Górski: Model niszczenia zmęczeniowego spawanego złączy prostopadłych płyt. Przegląd Spawalnictwa vol.83, nr 4, s.49-53, 2011.

[5] P. Stasiuk, A. Karolczuk, W. Kuczko „Rozkład naprężeń w krzyżowym złączu spawanym z uwzględnieniem rzeczywistego kształtu spoiny" Przegląd Spawalnictwa vol.86, nr 1, s.29-33, 2014.

[6] Oczoś K.E., Kawalec A., Kształtowanie metali lekkich, Wydawnictwo Naukowe PWN, Warszawa 2012.

[7] Ruszaj A., „Bioinspiracja w rozwiązywaniu problemów technicznych”; Szkoła Naukowa Obróbek Erozyjnych - Artykuły naukowe z 2015 r., Mechanik 2015 (12) $255-260$.

[8] Ruszaj A., Bioinspiracje w projektowaniu konstrukcji lekkich, Mechanik $2016(2)$
[9] Shu L.H, Ueda K., Chiu I., Cheong H., "Biologically inspired design", CIRP Annals - Manufacturing Technology 60 (2011) 673 - 693.

[10] Luriie-Luke E., "Product and technology innovation: What can biomimicry inspire"; Biotechnology Advances 32 (2014) 1494 - 1505.

[11] M. Grigorian, "Biomimicry and Theory of Structures - Design Methodology Transfer from Trees to Moment Frames", Journal of Bionic Engineering 11 (2014) 638-648.

[12] L. Tadrist, M. Saudreau, E. de Langre, "Wind and grawity mechanical effect leaf inclination angles", Journal of Theoretical Biology 341 (2014) 9-16.

[13] L. Zhao, J. Ma, W. Chen, H. Guo., "Lightweight Design and Verification of Gantry Machining Center Crossbeam Based on Structural Bionic", Journal of Bionic Engineering 8 (2011), 201-206.

[14] Z. Chen, S. Lu, X. Song, H. Zhang, W. Yang, H. Zhou, "Effects of bionic units on the fatigue wear of gray iron surface with different shapes and distributions", Optics \& Laser Technology 66 (2015) 166-174.

[15] J. Lu, CH. Yang, L. Zhang, A. Feng, Y. Jang, "Mechanical Properties and Microstructure of Bionic Non-Smooth Stainless Steel Surface by Laser Multiple Processing", Journal of Bionic Engineering 6 (2009) 180 - 185. 